\title{
Evidence of ongoing convergence within ASEAN
}

\begin{abstract}
This study provides evidence of ongoing real macroeconomic convergence of the founding members of ASEAN namely, Indonesia, Malaysia, the Philippines, Singapore and Thailand. Firstly, the long run macroeconomic relationship of ASEAN-5 is measured by their respective real gross domestic product. Secondly, the ongoing convergence of ASEAN-5 is examined. The empirical findings suggest that there is long run macroeconomic linkages and ongoing convergence among ASEAN-5. Hence, ASEAN-5 is deemed compatible but ASEAN's effort of re-organizing its supportive institutions will further improve the compatibility of its members. However, besides outstanding macroeconomic performance, the realization of a serious economic union would also depend on political stability and the sincerity of political leaders.
\end{abstract}

Keyword: ASEAN; Ongoing convergence; Cointegration 